\title{
Interlayer-free Glucose Carbonised Template Silica Membranes for Brine Water Desalination
}

\author{
Dwi Rasy Mujiyanti ${ }^{1}$, Muthia Elma $^{2, *}$, and Mufidah Amalia ${ }^{1}$ \\ ${ }^{1}$ Chemistry Department, Faculty of Mathematics and Natural Science, Lambung Mangkurat \\ University, Banjarbaru 70714, Indonesia \\ ${ }^{2}$ Chemical Engineering Department, Faculty of Engineering, Lambung Mangkurat University, \\ Banjarbaru 70714, Indonesia
}

\begin{abstract}
Interlayer-free glucose carbonized template silica membranes based on tetraethyl orthosilicate (TEOS) and glucose were successfully prepared using an acid-base catalysed sol-gel method for artificial brine water desalination $(7.5 \% \mathrm{wt} \mathrm{NaCl}$ solution \%) at temperatures range from 25, 40 and $60{ }^{\circ} \mathrm{C}$. These membranes calcined at 250 and $400{ }^{\circ} \mathrm{C}$. The membranes were fabricated through sol-gel process by using TEOS (tetraethyl orthosilicate); ethanol; nitric acid; ammonia; aquadest and glucose as a template. By molar ratio is 1: 38: 0.0007: 0.0003: 5 and $0.25 \% ; 0.5 \%, 1 \% \mathrm{w} / \mathrm{v}$ glucose as template. The results show the highest water fluxes of $1.8,2.2$ and $4.8 \mathrm{~kg} \mathrm{~m}^{-2} \mathrm{~h}^{-1}$ for 25,40 and $60{ }^{\circ} \mathrm{C}$ desalination process with excellent salt rejections of $99.5,99.5$ and $99.7 \%$, respectively. It was found that the higher the $\mathrm{NaCl}$ solution temperature as feed solution as well as glucose concentration $(0.25 \%$ to $1 \% \mathrm{wt})$ as template attached in the silica matrixes, the higher water fluxes even though the salt rejection remain the same. This study demonstrates that the organosilica membranes offered the carbonized silica mesostructure membranes with excellent separation of water from the hydrated salt ions, particularly for processing brine salt solutions.
\end{abstract}

Keywords: interlayer-free, glucose, silica-carbon membrane, desalination

\section{Introduction}

Water is a basic need of life. Especially for people, water is the most thing needed for domestic needs. Currently, water becomes a problem occurred almost all over of the world. It is due to the rapid population growth and the climate change. It was reported that there is only $3 \%$ of total consumable water on earth. The remaining $97 \%$ of the volume of water is salty [1]. As consequence, saline water cannot be utilised for daily need and can cause health problems. Furthermore, the World Health Organization (WHO) stated that more than $15 \%$ of the world's population does not have access to adequate drinking water $[2,3]$.

One way to overcome this water problem is by applying membrane technology via desalination. This process is applied by separating salt ions and water molecules using

*Corresponding author: melma@ulm.ac.id 
silica based membranes. The materials of membranes are silica glucose template membranes as carbon source. This membrane follow water desalination process via pervaporation to save energy as well as cost reduction. This desalination process has an environmentally friendly, energy-efficient, low operating cost and minimal use of chemicals [4-11]. In addition, this method is an attractive option for further investigation. Currently around $43.5 \%$ of worldwide desalination systems are still using thermal technology, where this technology has shortcomings in its application such as the amount of energy required to produce every volume $\left(\mathrm{m}^{3}\right)$ of clean water.

Pervaporation is part of desalination process that show low energy consumption. The energy requirements is one of reducing cost of the entire process. Furthermore, it is because of high efficiency, ease of operation, energy-saving and non-chemical use (Wang et al., 2012). The silica membranes, for example, is one of best material that enable to separate the molecules well during separation. This type of membranes is working excellently by employing sol-gel process (Elma et al., 2013). These membranes have smaller pore size, allowing water to diffuse on the membrane and inhibit the passage of salt ions (Lin et al., 2012).

Currently, inorganic membrane is an excellent technology in "water treatment" and widely used in the industry and is continuously developed for the last 30 years, one of which is the silica membrane. Recently, the silica membrane showed high stability in water by carbonizing the silica matrix with the non-ligand template in the gas separation process and desalination $[8,12]$. In this research, the carbonization of silica membrane templated from glucose was evaluated using artificial saline water $(7.5 \%$, brine water) through desalination via pervaporation process.

\section{Material and Methods}

\subsection{Xerogel: Synthesis and Characterization}

Silica sol were synthesised by a two-step acid-base sol-gel method using tetraethyl orthosilicate (TEOS, Merck) and glucose as a template, ethanol (EtOH) and water as solvents, and dilute nitric acid (0.0008 $\mathrm{M} \mathrm{HNO}_{3}$, Merck) and ammonia $\left(\mathrm{NH}_{3}, 25 \%\right.$, Merck). In the first step, TEOS solution was put drop-wise into ethanol and stirred for $5 \mathrm{~min}$ at $0{ }^{\circ} \mathrm{C}$ followed by slow addition of $\mathrm{HNO}_{3}$. Then, the solution was refluxed for $1 \mathrm{~h}$ at $50{ }^{\circ} \mathrm{C}$. The second step involves the base-catalysed polycondensation by drop-wise addition of $\mathrm{NH}_{3}$ diluted in ethanol into the acidified silica sol and reflux was continued for another $2 \mathrm{~h}$. At the end of $3 \mathrm{~h}$ refluxing the sols $\mathrm{pH}$ was measured to be approximately $\sim 6$, which is above the isoelectric point of silica $(\mathrm{pH} \mathrm{1-3)}$ and it is therefore basic. This method was explained in our previous work $[5,7,13]$. Glucose powder was then added and further stirred at room temperature for $45 \mathrm{~min}$ into silica sols in order to obtain the resultant sol. The final molar ratios of the TEOS:EtOH: $\mathrm{HNO}_{3}: \mathrm{H}_{2} \mathrm{O}: \mathrm{NH}_{3}:$ Glucose mixture sols were determined to be 1:38:0.0007:5:0.003:y where y (glucose) was varied from $0.25 \%, 0.5 \%$ and $1 \% \mathrm{w} / \mathrm{v} \%$. The mixtures were then dried at $60{ }^{\circ} \mathrm{C}$ for $24 \mathrm{~h}$ in the oven to obtain the dried gel which was grounded into powder and calcined in at 250 and $400{ }^{\circ} \mathrm{C}$ for $1 \mathrm{~h}$ in the furnace. The xerogels were characterised by using X-ray Diffraction and FTIR at wavelength range 400 $4000 \mathrm{~cm}^{-1}$.

\subsection{The Synthesis Glucose-Silica Membrane and The Desalination Process}

Silica sols that has been synthesised above (before drying and calcined) were firstly templated with glucose dissolved with ethanol 1:0.9 to reduce the viscosity for membrane dip-coating. Thin membrane films were coated on macroporous alumina substrates $(\alpha-$ 
$\mathrm{Al}_{2} \mathrm{O}_{3}$ tubular support $(\phi \approx 100 \mathrm{~nm})$, Ceramic Oxide Fabricates, Australia) using the asprepared glucose-Si sols via a dip-coating process with a dwell time of $2 \mathrm{~min}$ and a dipping and withdrawal rate of 10 and $5 \mathrm{~cm} / \mathrm{min}$, respectively. After the deposition of each layer, the membrane layer then calcined according to the same treatment described above for the xerogels. This cycle of dip coating and calcination was repeated four times (layers) to obtain high quality membranes with high salt rejection. The membrane was assembled into a classical pervaporation setup for desalination experiments. The membrane was blocked at one end and connected to a cold trap (immersed in liquid nitrogen) and vacuum pump operating at $1.5 \mathrm{kPa}$ at the other end. The membrane was immersed in a tank containing saline feed solution. The feed solutions were prepared with sodium chloride $(\mathrm{NaCl}$, SigmaAldrich) dissolved in deionised water with concentration $7.5 \mathrm{wt} \%$ and temperature was varied from 25 (room temperature), 40 and $60{ }^{\circ} \mathrm{C}$ which was controlled via a thermometer and hotplate. The feed solution was under constant stirring and recirculation to prevent concentration polarisation on the contact membrane side. The water flux, $\mathrm{F}\left(\mathrm{kg} \mathrm{m}^{-2} \mathrm{~h}^{-1} 1\right)$, was determined based on the equation $F=m /(A \Delta t)$, where $\mathrm{m}$ is the mass of permeate $(\mathrm{kg})$ retained in the cold trap, $\mathrm{A}$ is the surface-active area $\left(\mathrm{m}^{2}\right)$ of the membrane and $\Delta \mathrm{t}$ is the time measurement (h). The salt rejection, $\mathrm{R}(\%)$, was calculated as $R=(C f-C p) / C f x$ $100 \%$, where $C f$ and $C p$ are the feed and permeate concentrations of salt (wt \%). The salt concentrations were correlated to conductivities of the retentate and permeate solutions determined by a conductivity meter.

\section{Result and Discussion}

\subsection{Silica Sol}

Silica sol is the final product of sol-gel making process by reacting TEOS precursor (Tetraethly orthosilicate) in ethanol and with the aid of acid and base catalysts, namely nitric and ammonia. In the manufacture of silica sol, occurs several stages of the process of hydrolysis, condensation of alcohol and water condensation. In the first reflux, there is silanol formation $(\mathrm{Si}-\mathrm{OH})$ under acidic conditions $(\mathrm{pH} \sim 3)$ by hydrolysis process when TEOS precursor is dissolved into ethanol solution and will be hydrolyzed by addition of water and nitric acid catalyst. This hydrolysis will replace the alkoxy group (-OR) with the hydroxy group (-OH). During the hydrolysis process, the (-OR) group of TEOS will react with water molecules, thus forming silanol. The reaction can be seen in the following equation.

$$
\mathrm{Si}-\mathrm{OR}+\mathrm{H}_{2} \mathrm{O} \rightarrow \mathrm{Si}-\mathrm{OH}+\mathrm{ROH}
$$

In the second reflux, there is the formation of siloxane ( $\mathrm{Si}-\mathrm{O}-\mathrm{Si}$ ) by the condensation process. The result of the hydrolysis reaction $(\mathrm{Si}-\mathrm{OH})$ will react with TEOS and with the auxiliary base catalyst (ammonia) to allow condensation of the alcohol and to produce siloxane. The addition of this ammonia will increase the $\mathrm{pH}$ value greater than 4 . In this reaction, the ethanol produced is excessive resulting in the re-forming of the siloxane by the reaction of water condensation. The reaction that occurs can be seen in the following equation.

$$
\begin{aligned}
& \mathrm{Si}-\mathrm{OR}+\mathrm{HO}-\mathrm{Si} \rightarrow \mathrm{Si}-\mathrm{O}-\mathrm{Si}+\mathrm{ROH} \\
& \mathrm{Si}-\mathrm{OH}+\mathrm{HO}-\mathrm{Si} \rightarrow \mathrm{Si}-\mathrm{O}-\mathrm{Si}+\mathrm{H}_{2} \mathrm{O}
\end{aligned}
$$

The result of this sol-gel process will produce silica sol which has a $\mathrm{pH}$ value of 6 . $\mathrm{pH} 6$ is an optimum $\mathrm{pH}$ because at this $\mathrm{pH}$ will produce mesoporous membrane pores $[5,7,13]$, 
which is larger in pore size compared to with the size of water molecules but smaller when compared with the size of salt molecules. According to our previous work, at higher $\mathrm{pH}$ contain much siloxanes so that the membrane pores will be larger and the resulting viscous soles will lead to a rapid gel-forming process. At lower $\mathrm{pH}$, silanol content is higher than siloxane, resulting in smaller membrane pores. Therefore, $\mathrm{pH} 6$ was selected in this study. In this research, silica soles are clear and not very viscous, so it can be used to coat the membrane support well.

\subsection{The Characterization of Xerogel}

Fourier Transform Infra-Red (FTIR) was performed to analyze the functional group on the compound, a silica xerogel sample. The siloxane and siloxane groups are known to affect the pore size of the membrane, since the purpose of making this xerogel is to be used as thin film membrane coating, so it is important to know whether there are two groups $[4,9$, $11,12,14]$. From the analysis of FTIR xerogel silica-glucose can be seen in the following Figure 1.

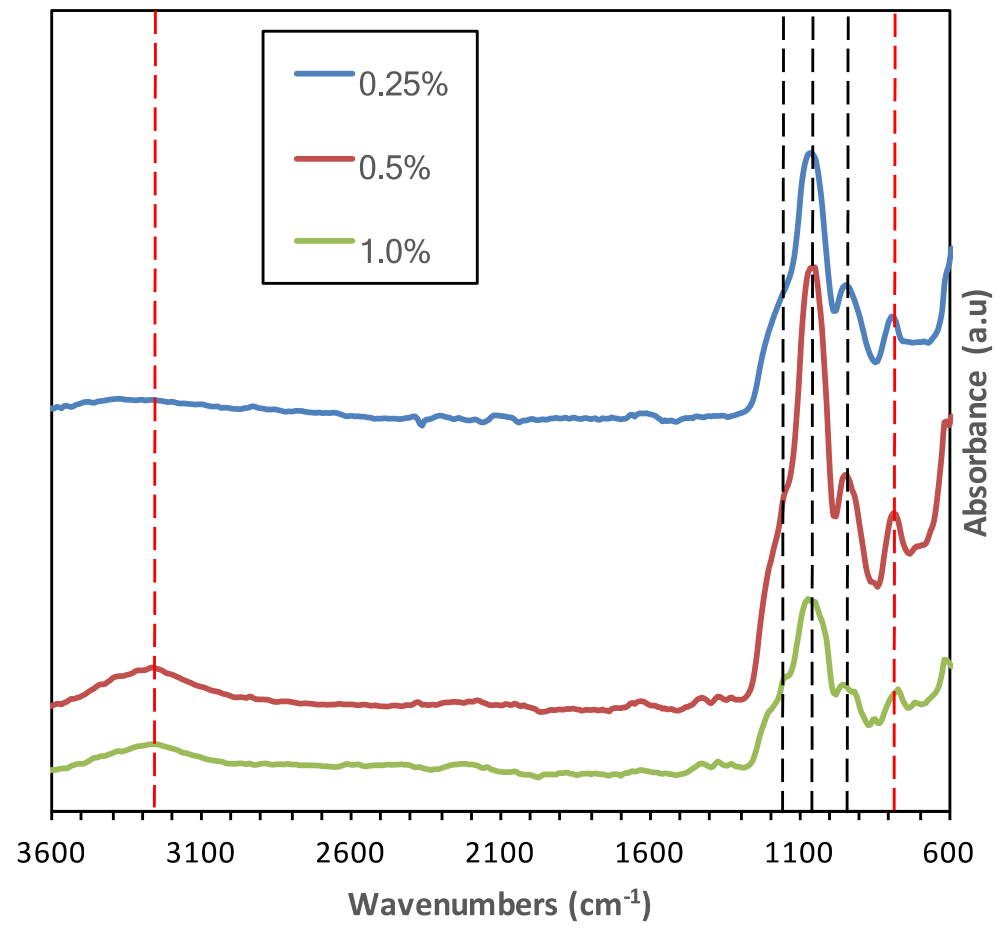

Fig. 1. FTIR graph of xerogel samples with glucose concentration $0.25 ; 0.5 ; 1 \% \mathrm{w} / \mathrm{v}$

Figure. 1 shows the FTIR spectra of the silica-glucose xerogel sample without calcination. In the non-calcined xerogel sample there were 4 peaks indicating the presence of Si-O-Si (siloxane) groups at wave numbers $1070 \mathrm{~cm}^{-1}$ and $1160 \mathrm{~cm}^{-1}$, Si-OH (silanol) groups at wave numbers $950 \mathrm{~cm}^{-1}$ and the $\mathrm{CH}_{2}$ vibration that appears around 840 and 3.250 $\mathrm{cm}^{-1}[5,10,12,15]$. The band at $3.250 \mathrm{~cm}^{-1}$ for sample 0.5 and $1 \%$ glucose show a strong infrared band of $\mathrm{C}-\mathrm{H}$. However, for the $0.25 \%$ glucose show a very low stretching vibration. 


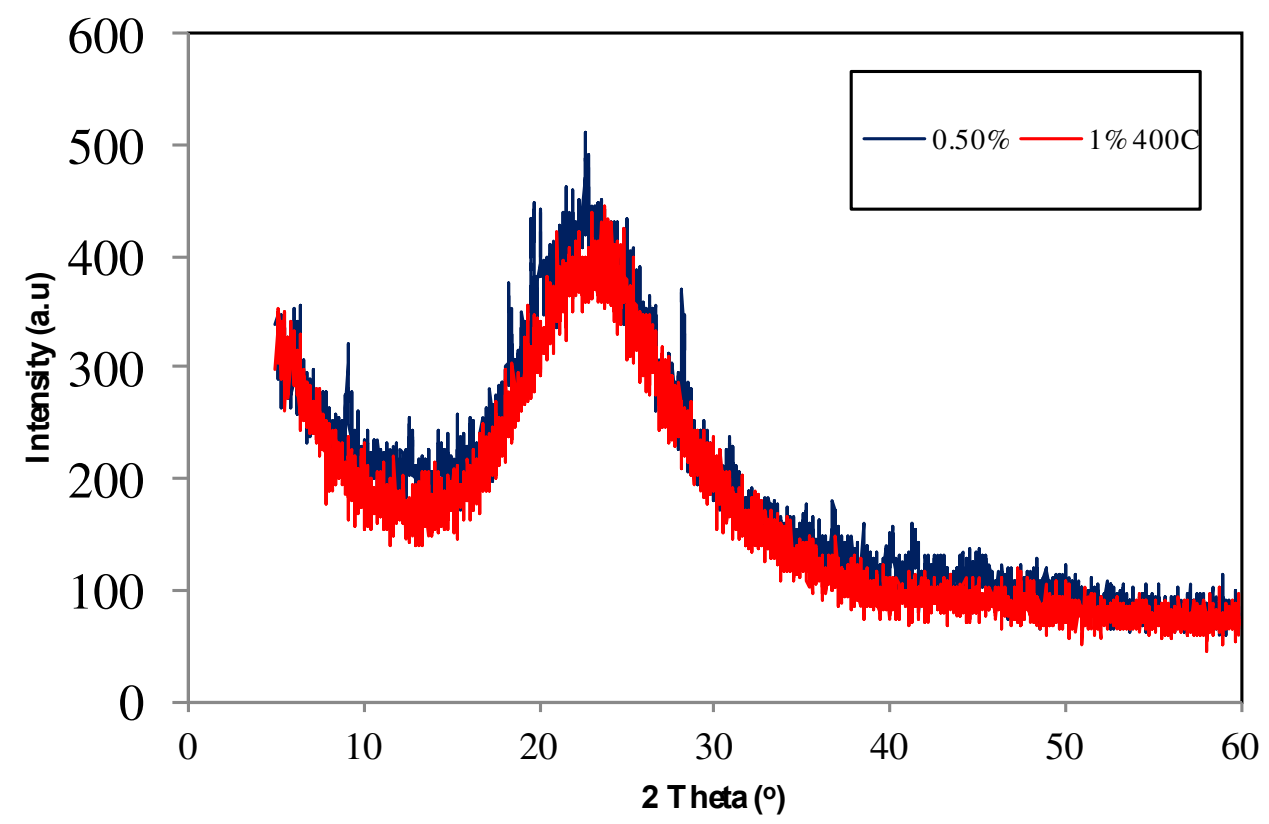

Fig. 2. XRD graph of 0.5 and $1 \% \mathrm{w} / \mathrm{v}$ xerogel of silica-glucose template membranes calcined at $400^{\circ} \mathrm{C}$

Pure silica is a compound having amorphous structure. In order to know the structure of this compounds, the silica-glucose sols were dried and powdered in the oven $\left(24 \mathrm{~h}, 60^{\circ} \mathrm{C}\right)$. It is then calcined at $400^{\circ} \mathrm{C}$ to form xerogel. Figure 2 shows, the trend between 0.5 and $1 \%$ glucose as a template looks similar and there is significant peaks between them. Also, from the diffraction results obtained that the intensity is very close to each other which indicates that the structure of the silica-glucose xerogel for both samples are amorphous structures. However, several intensities found for samples $0.5 \%$. In other word, the silica-glucose $(0.5 \% \mathrm{w} / \mathrm{v})$ is more amorphous than $1.0 \%$.

\subsection{The Performance of Membrane}

The performance of the glucose-silica membranes in the desalination process via pervaporation can be seen from the values obtained in Fig. 3. The value of water flux increases when the feed temperature is increased. However, the salt rejection show excellent value $(>93 \%)$. In this work, the membrane evaluated at $7.5 \% \mathrm{NaCl}$ feed concentration (artificial brine salt water). Figure 3 shows the value of water flux and salt rejection on 4 layers' silica-glucose membranes at three different feed temperatures. 


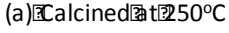

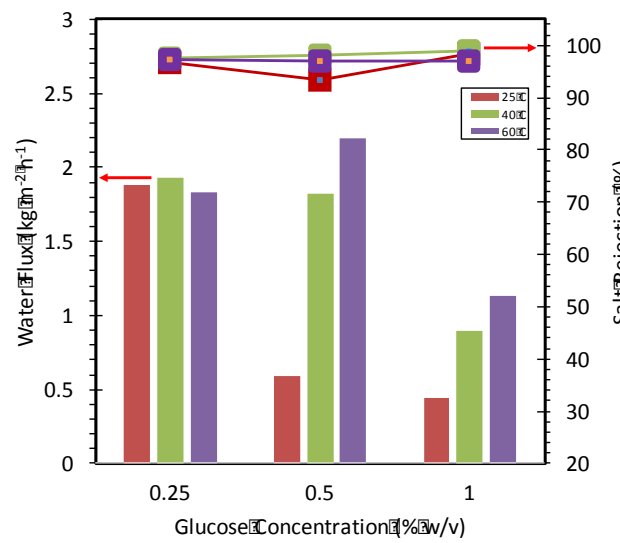

(b) ?Calcined解的 $00^{\circ} \mathrm{C}$

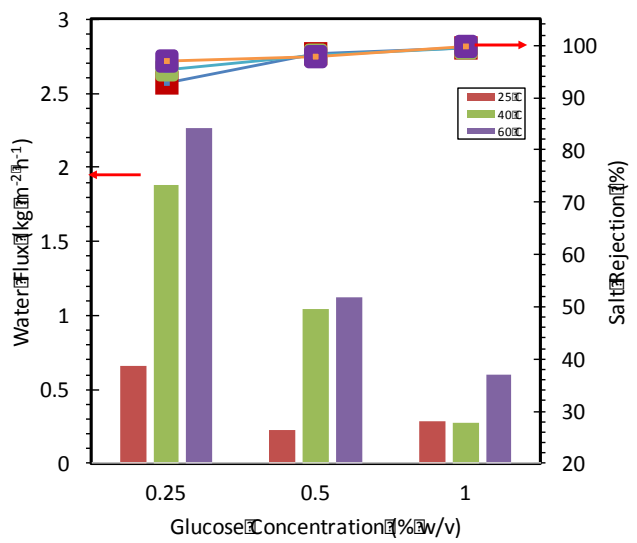

Figure 3. Performance of Si-Glucose Membranes $(0.25 ; 0.5 \& 1.0 \% \mathrm{w} / \mathrm{v}$ at feed temperature 25,40 $\& 60^{\circ} \mathrm{C}$.

From Figure 3 (a) and (b) can be seen the value of water flux and salt rejection produced by silica-glucose membranes evaluated through water desalination via pervaporation, Figure 3 (a) shows the water flux and salt rejection for silica-glucose membranes using $0.25 ; 0.5$ and $1 \% \mathrm{w} / \mathrm{v}$ glucose as a template and evaluated via evaporation employing artificial $7.5 \%$ saline water. This pervaporation was taken place in three temperatures $\left(25,40\right.$ and $\left.60{ }^{\circ} \mathrm{C}\right)$. the water flux varied between temperature conditions as well as glucose concentration as template in silica-glucose membranes. They varied from 0.44 to $2.20 \mathrm{~kg} \mathrm{~m}^{-2} \mathrm{~h}^{-1}$ from 25 to $60{ }^{\circ} \mathrm{C}$ as feed temperatures. Interestingly, the salt rejection is all excellent $>93 \%$. Similar to figure 3 (a), figure 3 (b) show similar trend to figure 3 (a). Figure 3 (a) show silica-glucose membranes calcined at $250{ }^{\circ} \mathrm{C}$ and figure 3 (b) is calcined at $400{ }^{\circ} \mathrm{C}$. The water flux for membranes calcined at $400{ }^{\circ} \mathrm{C}$ show 0.60 to 2.26 $\mathrm{kg} \mathrm{m}^{-2} \mathrm{~h}^{-1}$. It is clearly evaluated that the water fluxes for membranes calcined at $400{ }^{\circ} \mathrm{C}$ show a bit lower than membrane calcines at $250{ }^{\circ} \mathrm{C}\left(0.22\right.$ to $\left.2.28 \mathrm{~kg} \mathrm{~m}^{-2} \mathrm{~h}^{-1}\right)$ where the trend of salt rejection remain similar. However, if compare the influence between the addition of glucose as template and water fluxes, the water fluxes reduce $60 \%$ when the glucose concentration was added $(0.25$ to $1.0 \% \mathrm{w} / \mathrm{v}$ glucose $)$. It can be explained that this water fluxes of membranes are a bit lower compare to our previous work [8, 12]. It is due to different material to get carbon source. Also, the method of calcination process could be an issue that affect the thickness of membranes itself. The calcination method of this work is Rapid Thermal Processing.

\section{Conclusions}

Silica-glucose membranes have been successfully synthesised using the acid-base catalysed sol-gel method. The C-H stretching vibration through infrared spectrophotometry show higher peak $\left(3.250 \mathrm{~cm}^{-1}\right)$ when the glucose concentration is increased in the silica matrix. Also, the silica-glucose membranes show excellent performance with salt rejection $>93 \%$ and water fluxes range from 0.22 to $2.28 \mathrm{~kg} \mathrm{~m}^{-2} \mathrm{~h}^{-1}$ in various feed temperature $(25,40$ and $60{ }^{\circ} \mathrm{C}$ ). This can be summarized that by adding glucose as carbon source and template, the network of silica based membranes become stronger even though the value of water fluxes remains a bit lower 


\section{Acknowledgement}

This research paper was supported by Kurita-AIT Research Grant 2017. Muthia Elma thanks to Post-Doctoral Grant 2017-2018, Directorate of Research and Community Service, the Ministry of Research, Technology and Higher Education Republic of Indonesia and Muthia Elma also acknowledge to the financial support research grant of Postgraduate Programmes 2018 Lambung Mangkurat University and Australian Alumni Scheme Batch II 2018. And also, authors thank to Technology Process Laboratory of Chemical Engineering Department, Engineering Faculty, Lambung Mangkurat University for the research facilities.

\section{References}

1. Soteris A. Kalogirou. Progress in Energy and Combustion Science. 31. 242-281. (2005)

2. World Health Organization and United Nations International Children's Fund. (2010)

3. Foerch, Wiebke, Ingrid Althoff, and Gerd Foerch. Encyclopedia of environment and society. 24. 1922. (2007)

4. Tianlong Zhang, Muthia Elma, Fengwei Xie, Julius Motuzas, Xiwang Zhang, and David K. Wang. Separation and Purification Technology. 206. 99-106. (2018)

5. Elma Muthia, Riskawati Nur, and Marhamah. IOP Conference Series: Earth and Environmental Science. 175. 012006. (2018)

6. Elma Muthia and Setyawan Heru. IOP Conference Series: Earth and Environmental Science. 175. 012008. (2018)

7. Elma Muthia, Hairullah, and Assyaifi Zaini Lambri. IOP Conference Series: Earth and Environmental Science. 175. 012009. (2018)

8. Elma Muthia, Fitriani, Rakhman Arief, and Hidayati Rahmi. IOP Conference Series: Earth and Environmental Science. 175. 012007. (2018)

9. Hong Yang, Muthia Elma, David K. Wang, Julius Motuzas, and João C. Diniz da Costa. Journal of Membrane Science. 523. 197-204. (2017)

10. Muthia Elma, Christelle Yacou, João Costa, and David Wang. Membranes. 3. 136150. (2013)

11. Muthia Elma, Christelle Yacou, David K. Wang, Simon Smart, and João C. Diniz da Costa. Water. 4. 629-649. (2012)

12. Muthia Elma, David K. Wang, Christelle Yacou, and João C. Diniz da Costa. Journal of Membrane Science. 475. 376-383. (2015)

13. Muthia Elma, Christelle Yacou, João C. Diniz da Costa, and David K. Wang. 3. 136150. (2013)

14. David K. Wang, Muthia Elma, Julius Motuzas, Wen-Che Hou, Fengwei Xie, and Xiwang Zhang. Journal of Membrane Science. 524. 163-173. (2017)

15. Bradley P. Ladewig, Ying Han Tan, Chun Xiang C. Lin, Katharina Ladewig, João C. Diniz da Costa, and Simon Smart. Materials. 4. 845-856. (2011) 